\title{
The Effectiveness of An Educational Program Based on Pictures and Graphics in Developing Some Spatial and Temporal Concepts among Kindergarten Children
}

\author{
Dr. Abdelraouf Hameed Alyamani ${ }^{1}$, Dr. Mohammed bani Khaled ${ }^{1}$ \& Dr. Safia M Jabali ${ }^{1}$ \\ ${ }^{1}$ College of Educational Sciences, Isra University, Department of Child Education, Jordan \\ Correspondence: College of Educational Sciences, Isra University, Department of Child Education, Jordan.
}

Received: December 29, 2020

Accepted: January 28, 2021

Online Published: January 29, 2021

doi:10.5430/ijhe.v10n1p319

URL: https://doi.org/10.5430/ijhe.v10n1p319

\begin{abstract}
The study aimed to identify the effectiveness of an educational program based on images and graphics in developing some spatial and temporal concepts among kindergarten children. The researchers used the semi-experimental approach, and the sample of the study, chosen randomly, consisted of (50) children and distributed among the two study groups (25) groups. Experimental and (25) control groups. The researchers prepared the study tools represented by the educational program and a test that measures temporal and spatial concepts after confirming their validity and stability. The results of the study showed statistically significant differences between the members of the two groups in favor of the experimental group, and the study recommended including this program in kindergarten curricula.
\end{abstract}

Keywords: efficiency, program, concepts, place, time.

\section{Introduction}

The kindergarten stage is considered one of the most important stages in an individual's life in terms of the growth of his personality in a balanced, comprehensive and integrated manner, in all its aspects, hence the importance of working on preparing specialized scientific programs based on programs, games and pillars that will develop multiple aspects for children, including the development of the mental and cognitive side and the acquisition of concepts that he is able to employ in knowing the surrounding environment and interacting with it, and forming new concepts even if in a simple and modest manner at this stage, and the process of forming a concept is a dynamic and phased process that requires successive processes, which the child practices through the presence of certain situations, and then the process concept formation is the first stage in its concept development, upon which other stages are built.

And the focused on this period of an individual's life, many scholars in their research and studies considered that childhood is very important, and they unanimously agreed on that, so that almost all theorists and psychologists have unanimously agreed on the importance of early childhood, and it is very important. The school of psychoanalysis, for example, she focused on this stage with great focus, and Freud believes that the personality of the individual is formed during the first five years of the child's life, which constitutes early childhood, three years of which he considers one of the critical stages of development in which childhood experiences constitute the personality of the individual, as well as Anna Freud, was interested in this However, she said that childhood experiences are present problems for children (Al-Mallah, 2016).

It is very important to pay attention to the kindergarten stage, given its great importance, which helps the child to develop comprehensively. Things have been simplified and various opportunities have been made available to him to grow soundly, expand his perceptions and refine his skills through various games and activities, as well as satisfy his various needs and direct his inclinations it is true (Hariri, 2003).

The kindergarten stage extends from (4-6) years, during which the child begins to learn a set of concepts from the concrete to the abstract, and gradually according to the level of each child. Often kindergarten children can learn words without understanding their meanings, and that their meanings are far from the correct meanings, so their ideas on animals and plants, distant times, and distant places, ideas are largely unclear (Boutros, 2008).

The kindergarten stage is considered a non-teaching stage, rather it is concerned with the development of the child in all aspects of his personality, in a comprehensive and balanced manner in terms of his capabilities, skills, tendencies, 
and trends, and the child is considered the focus on which kindergarten programs and activities are based, and he responds positively as he has the freedom and a suitable environment, and the right place (Eid, 2006).

At this stage, he notes the beginnings of forming concepts such as the concept of time and the concept of number, and gradually the child uses his language to form living concepts, that is, tangible concepts of people, things and foods. Abstract concepts grow in the later stages (Al-Felfili, 2009).

Children's perceptions of the world around them can be revealed through training and developing their mental abilities, and on replacing the wrong ones with the correct ones, and the kindergarten focuses its strength on developing young people's awareness and attention, their imagination and thinking in addition to the development of their language, and through mental training, children get acquainted with simple concepts of time, and the quantity and space, and on comparing certain quantities to each other, and on forming simple relationships between shapes and numbers (Adas and Musleh, 1984).

Children are interested in time through the environment that they coexist with within their family life, and it is possible that they have a simple concept of it when we tell them this is breakfast time or this is the time of your father's return from work, or it is time for bed, and the child's awareness of these temporal concepts increases when he joins In kindergarten, and he goes to school, he learns that his school day begins at a certain time and ends at a certain time, and he realizes in both home and school that days have specific names and that they are consecutive, and they may accept to know the names of the days on which the school is not working or working. The annual accidents and events that we experience, such as national holidays, official holidays and his birthday, reinforce his concept of time, in a practical way without the need for explanation and clarification (Fahmy, 2012).

The child begins in the stage of sensory work, forming concepts as it is a developmental stage, and begins to get to know his surrounding environment, its elements and assets, through sensory work, and he gets new experiences by dealing with the things around him, which helps in the development of his skills through his actions and his contacts with the environment Surrounding (Mahadin, 2003). Given the importance of concepts in general and the spatial and temporal concepts in particular for the kindergarten child, preparing programs and activities for children is necessary in order to develop these concepts in the child at this stage.

\section{The Problem of the Study}

The problem of this study is that children at this age are not able to know concepts related to space or time in an abstract way, and in order to acquire some of these concepts at this age stage, they need programs that focus on developing these concepts in them through the sense of sight and linking the child's acquisition for such concepts with pictures at this age, they are considered as sensory stimuli that contribute to the acquisition of such concepts in a better way, and on the other hand, there are no studies according to the knowledge of researchers on this topic, and in view of the above, this study came to reveal the effectiveness of an educational program based on images and graphics in developing some spatial and temporal concepts of kindergarten children.

\section{The Importance of the Study}

The importance of this study is represented in the following:

\subsection{Theoretical Importance}

- The importance of this study is evidenced by the fact that it deals with the development of some temporal and spatial concepts in the kindergarten child, noting that there are no studies - according to the knowledge of the researchers that dealt with these concepts.

- It is expected that this study will contribute to the development of some Romanian and spatial concepts for kindergarten children.

- This study contributes to enriching the Arab library with such studies specialized in kindergartens, for use by researchers in the field of childhood.

- This study sheds light on the importance of building programs based on images and graphics in developing temporal, spatial and other concepts.

\subsection{Applied Importance}

- Experts and designers of kindergarten curricula can benefit from this study in designing programs based on images and graphics in developing temporal and spatial concepts for the kindergarten child.

- This study can contribute to the development of the existing kindergarten curricula, to make it richer in containing such programs that develop temporal and spatial concepts for the kindergarten child. 
- Kindergarten teachers benefit from them in building activities in the form of worksheets, which contribute to the development of temporal and spatial concepts among kindergarten children.

\section{The Questions of the Study}

This study came to try to answer the following main question:

The first question: What is the effectiveness of a program based on images and graphics in developing some temporal and spatial concepts in kindergarten children?

\section{The following Hypotheses are Divided from It}

- The first hypothesis: There are no statistically significant differences between the mean scores of the experimental group and the control group on testing temporal and spatial concepts in the pre-application.

- The second hypothesis: There are no statistically significant differences between the mean scores of the experimental group and the control group on the test of temporal and spatial concepts based on images in the post-application.

- The third hypothesis: There are no statistically significant differences between the mean scores of the experimental group in the temporal and spatial concepts test before and after the application of the program.

\section{The Limits of the Study}

- Objective limits: The study dealt with the effectiveness of a program based on images and graphics in developing some temporal and spatial concepts in kindergarten children.

- Human limits: It includes the study members, who are a sample of Riyadh children, whose ages range from (5-6) years, in the Education Directorate in Mafraq Governorate.

- Spatial boundaries: The study was implemented in the kindergarten of Al Hamra Girls School in the Education Directorate in Mafraq Governorate.

- Temporal limits: The study was implemented in the first semester of the academic year 2018/2019.

\section{The Terminology of Study}

- Effectiveness: Is the ability to satisfactorily achieve its goals when used by those for whom it was prepared under the conditions under which it is likely to use the program in the future (Isa, 1997). Effectiveness means in the current study the extent of the impact that the experiment has on the dependent variable.

- Concepts: "They are common qualities in a word, idea, or mental conception, whether abstract or tangible, with common characteristics and characteristics expressed in a word or sentence" (Bawazir and Qurban, 2011, 43).

- Spatial concepts: "It is one of the geographical concepts that refer to the dimensions of the place such as "above, below, in front, behind the side, right, left, inside, outside, far, close... etc.", and it refers to different places such as "a mountain, A river, a valley, a plain ... etc.", "It is one of the simplest concepts of place that a child can learn to understand his external surroundings and the dimensions of the object" (Bawazir and Qurban, 2011, 168). Spatial concepts test prepared for this purpose.

- Temporal concepts: "It is the stated extent of the succession of events, which is based on social factors and a sense of movement, and it may be an objective social time that is measurable, such as a clock, and a subjective variable time specific to individuals and their needs" (Bawazir and Qurban, 2011, 64) Procedurally, in the current study, it is defined by the degree that kindergarten children obtain on the temporal concepts test prepared for this purpose.

- Kindergarten children: They are children who enroll in kindergarten at the age of three or four years and extend to the sixth year, or when the child enrolls in the primary stage (Sharif, 2014, 81).

\section{Methods}

- Calculation of test reliability by Cronbach's Alpha.

- Pearson correlation coefficient.

- Wilcoxon test.

- Mann-Whitney test.

- Arithmetic means and standard deviations. 


\section{Theoretical Literature}

The knowledge and learning of concepts are closely related to the capabilities of the learner himself. Curriculum experts and specialists develop procedures and select materials that will provide learners with concepts with an advanced level of success (Godwin and Klausmeier, 1995).

Through the children's interaction with the stimuli, attitudes and experiences they are exposed to, we find that concepts are formed in them, which helps in forming mental images indicated by a symbol, name or name-bearing the meaning of this concept, and thus concepts are formed in the child firsthand and at an early stage, It increases his linguistic wealth and increases his knowledge and experiences that help him learn and acquire more concepts (Bawazir and Qurban, 2011).

Hergesheimer (2000) asserts that temporal concepts represent the core of the understanding that we are trying to achieve, as it is the way in which we relate ideas across time and space, and most of the time these concepts are used and taught at all times, but they are sometimes studied without care and attention.

The concept of time is closely related to the individual's internal rhythms, and cultural adaptation, his response to time, and when the individual has a series of expectations related to the vortex of relationships, processes and events, this adaptation is due to childhood, and one of the most important forms of knowledge in a child is his knowledge of the cycle of things (Abd Al-Majeed, 1978).

The concept of place for the child in terms of his perception of spatial relationships remains limited, and this concept develops with time when the child grows, so we find that while playing in the kindergarten yard, children use things to separate spaces, they use tree trunks, and the child cannot properly estimate the spatial space. He tries to place the big seat in a narrow space that cannot accommodate him, as well as tries to place the playing pieces in the wrong place, etc., which indicates the child's lack of awareness of spaces, voids and spatial space, and with the use of models of certain games, the child's perception of the concept of place grows (Ibrahim and Boutros, 1997).

And though the child's contact with others, his awareness of the concept of place grows, so he speaks in a low voice when his colleague is next to him and raises his voice if he wants to speak with one of the children far away from him, and whispered his voice if he wants to say a secret, and the child notices one of his parents when he speaks on the phone so he is His voice is low or loud sometimes, so the child imitates one of the mother's or father's parents in this matter while playing activities, which helps him to understand the concept of emptiness (Boutros, 2008).

Likewise, children are not interested in clear concepts of time at a young age, the young child does not have the meanings or perceptions of some terms such as, finally, immediately, tomorrow, yesterday, and they are not understood by him. Is it too far away and the child wishes that tomorrow this means now in order to enjoy the journey, and in order to help children understand the concepts of time, they must help them in the system in which the daily events took place (Al-Sherbiny, 1988). There are also many important mental concepts that a child acquires during the preschool period, from these concepts, the concept of quantity, size and the concept of place, and to acquire these concepts it was necessary to train children on the mental processes necessary for all of these concepts (Karmaldeen, 2001).

\subsection{Previous Studies}

Scott (1997) conducted a study aimed at measuring multiple concepts of time represented in the near future, compared to the distant future and the near and far past, and observation was used as a measurement tool by observers, and this study was conducted on a sample of children from age groups ranging from 3-6 years divided into three age groups, each group represents one year of age and includes 20 children. The results showed the progress of the older children in understanding these concepts compared to the young, especially in the use of expressions indicating the past, present and future, and methods of determining the differences between these times.

And Bani Khaled performed (2009) a study entitled preparing an educational program based on activities related to the axis of time, change and continuity, and its effect on the awareness of time. The basic tenth-grade students and their interpretation of historical events in the history study led to the education of the Northwestern Badia Brigade, where the study aimed to explain the impact of this program, and the study sample consisted of (157) male and female students from the tenth grade of basic school in public schools, and they were chosen in an available way, and the results of the study revealed the existence of statistically significant differences at the significance level $\alpha, 00,5$ in the development of awareness of time among tenth-grade students, in the study of history, and the presence of a statistically significant interaction The awareness of time is attributed to the gender variable, and the study recommended that similar studies be conducted at other levels. 
Abu Al-Jain (2012) conducted a study that tried to reveal the effectiveness of a training program to interact with technical drawings (pictures) in developing emotional intelligence in a sample of kindergarten children in Jordan. The quasi-experimental approach was used, as the program was applied to a sample of kindergarten children in the governorate. The capital and it consisted of (40) children and a girl in the kindergarten of Amman National Schools, they were divided into two experimental and control groups, and the Sullivan emotional intelligence test was applied to them, and the results of the study indicated that there were statistically significant differences in emotional intelligence among kindergarten children attributed to the training program and for the benefit of the experimental group.

Al-Felfili and Al-Ansi (2015) conducted a study entitled the effectiveness of an educational corner in the development of spatial intelligence and the differences in spatial intelligence, depending on the gender variable. The sample of the study consisted of (70) children from pre-school children in public schools in the capital, Sana'a, whose ages ranged from (5-6) years. They were distributed into two groups, one of which is experimental and its number is (35) children and a girl, and the other is a control number. 35) a child and a girl, and to achieve the research objectives, the following tools were used: the spatial intelligence test, the man drawing test, the educational corner, and the following results were reached: There are statistically significant individual differences in spatial intelligence between the mean scores of the experimental group children, and the mean scores of the children of the control group, in favor of the experimental group, and there are statistically significant differences in spatial intelligence between mean scores for males and average scores for females in favor of females, and the study recommended the importance of paying attention to the mental abilities of children through educational programs based on multiple theory of intelligence.

The Tarawneh study (2016) aimed to reveal the effectiveness of a training program based on analogue thinking in developing concepts (spatial, temporal, scientific, and social) among kindergarten students in Karak governorate, and it followed the quasi-experimental method, where the study sample consisted of (96) students. One of the kindergarten students in Karak governorate is divided into an experimental group and a control group, and they were chosen by the intentional method. The results of the study indicated that there are statistically significant differences between the experimental and control group in all the concepts included in the program, in favour of the experimental group.

Al-Shahwan (2017) conducted a study aimed at identifying the effectiveness of a computerized educational program in developing concepts of health and safety. The sample of the study, which was chosen randomly, consisted of (50) children and a girl, the second level (5-6) years, distributed among the two study groups (25) children and girls in the group, and (25) boys and girls in the control group. The study tools represented the health and safety concepts list and the educational program. And testing the concepts of health and safety for the kindergarten child after making sure of their validity and consistency, and the results showed that there are statistically significant differences in favor of the experimental group that was exposed to the computerized program, and the study recommended emphasizing the importance of the educational computer for children as one of the means that work to develop the concepts of safety and health in pre-school children.

Hammam (2018) conducted a study aimed at revealing the effectiveness of a counseling program in developing concepts of health awareness among kindergarten children. The study tools were applied to a sample of pre-school children in kindergarten (44) children and girls, whose ages range from (5-6) years. In the city of Najran, Saudi Arabia, in the second semester of 2018, the study used the quasi-experimental approach, and after implementing the program, the results of the study found statistically significant differences at the significance level $(0.05)$ between the mean scores of the experimental group children and the mean scores of the control group children in the post-measurement of concepts Health awareness for the benefit of the children of the experimental group after implementing the program. The study recommended amending the content of the Health and Safety Unit to include additional concepts such as the environment, health, and concepts related to health and disease.

\subsection{Commenting on Previous Studies}

By reviewing previous studies, it appears that these studies followed the experimental method, which was followed by the current study, and those studies used training programs to develop multiple concepts or skills and various intelligences, such as the study of Abu Al-Jain (2012) in the development of emotional intelligence, and the study of Tarawneh (2016) in developing Concepts (spatial, temporal, scientific, and social) among kindergarten students, the study of Hammam (2018) in the development of concepts of health awareness among kindergarten children, the study of Al-Felfili and Al-Ansi (2015) in the development of spatial intelligence, and the study of Al-Shahwan (2017) in the development of concepts of health and safety, As for the current study, it came to develop temporal and spatial concepts among kindergarten children, and the researchers did not find any study that used an educational program based on images and graphics in the development of some spatial and temporal concepts in kindergarten children, and 
this is what distinguishes the current study from those studies, in addition to its distinction in place It is the governorate of Mafraq in Jordan.

\section{Method and Procedures}

Study methodology: The researchers used in this study the quasi-experimental approach, based on testing two groups, the first is experimental, exposed to the program, and the other control, not exposed to the program.

\begin{tabular}{|c|c|c|c|c|c|}
\hline \multirow{2}{*}{$\begin{array}{l}\text { Exposing the } \\
\text { experimental group to } \\
\text { a program based on } \\
\text { images and graphics to } \\
\text { develop some spatial } \\
\text { and Roman concepts. }\end{array}$} & $\begin{array}{c}\text { An } \\
\text { experimental } \\
\text { group }\end{array}$ & \multirow{2}{*}{$\begin{array}{l}\text { Conducting a } \\
\text { pre-test for both } \\
\text { groups to } \\
\text { measure the } \\
\text { level of the two } \\
\text { groups }\end{array}$} & \multirow{2}{*}{$\begin{array}{l}\text { Application of the } \\
\text { program based on } \\
\text { images and } \\
\text { graphics to develop } \\
\text { some spatial and } \\
\text { temporal concepts }\end{array}$} & \multirow[t]{2}{*}{$\begin{array}{l}\text { After completing } \\
\text { the program, a } \\
\text { post-test is } \\
\text { applied }\end{array}$} & \multirow[t]{2}{*}{ Results } \\
\hline & $\begin{array}{l}\text { Control } \\
\text { group }\end{array}$ & & & & \\
\hline
\end{tabular}

Figure 1. the experimental design of the study

\section{Study population and sample}

The study population consists of all kindergartens in the governmental governorate of Mafraq for the year 2018/2019, where one of the kindergartens was chosen by a simple random method, and two groups were chosen randomly, namely Division (A) and Division $(\mathrm{C})$, then the experimental division was chosen in a simple random way, and Division (C) represents the experimental group and Division (A) represents the control group, chosen randomly.

Table 1. Distribution of the study sample in the experimental and control groups

\begin{tabular}{ccc}
\hline Test & Experimental group & Control group \\
\hline The pretest & 25 & 25 \\
Post-test & 24 & 23 \\
Total & Number of children who were absent after & In the experimental period \\
& excluding those who were absent & \\
\end{tabular}

\subsection{Study Variables}

- The independent variable: the program based on images and graphics is represented in the development of some temporal and spatial concepts among kindergarten children.

- The dependent variable: temporal and spatial concepts.

\section{2- Study Tools}

\section{The tools of this study consisted of the following:}

A program based on images and graphics, in the development of some spatial and temporal concepts of kindergarten children, as this program consists of four educational units, each unit contains appropriate educational experiences and activities based on images and graphics on the development of some temporal and spatial concepts, which the child receives inside the kindergarten Under the supervision of the teacher, the researchers referred to theoretical literature and previous studies, such as Bahader's study (2008) Abu Al-Jain (2012), Al-Felfili study (2013), and Al-Saeidy's study (2013). The researchers built the study program, where the philosophy of this program stems from that it is directed to children. Kindergarten and it is necessary to develop the child cognitively and mentally and to develop some concepts that help him to deal with the temporal and spatial dimensions properly and with the aim of developing some temporal and spatial concepts among kindergarten children, as important concepts in developing his mental and cognitive abilities. The program was evaluated through formative evaluation from the beginning the program until its completion through questions and discussions, then a final evaluation, which is an examination of temporal and spatial concepts, is conducted.

The researchers prepared a final examination of the temporal and spatial concepts illustrated to measure the effectiveness of the program in developing some temporal and spatial concepts among kindergarten children, taking advantage of educational literature and previous studies such as the study of Al-Filfili and Al-Ansi (2015), the study of Tarawneh (2016), the study of Al-Shadifat (2017), and the study of Al-Shahwan (2017). The preparation of the pictorial temporal and spatial concepts test required defining the purpose of the test, and that it is presented to kindergarten children who do not have the ability to write or read. The image should be clear, appropriate size, and its colors are appropriate and clear. The test method was a series, where the name of the child, his age and the date of the 
test is written on the cover of the test, then the image is presented to the child and the question is read to the child in a clear language and an appropriate speed, and the instructions of each question are clarified, and the child is given a score (1) when he gives a correct answer and a score of (0) when he gives a wrong answer.

\subsection{Program Validated}

After preparing the program, it was presented to a group of referees with specialization, academic experience and good reputation in the disciplines of curricula, teaching, psychology and child education, and all their observations and opinions were taken in terms of the suitability of the program for the kindergarten child, its objectives and the linguistic formulation, as the percentage of agreement between the arbitrators about the program was $89 \%$, Which indicates that the program is suitable for conducting such a study.

\subsection{Test Validation}

\section{The validity of the test was verified by two methods:}

- Outward honesty: where the test was presented to a group of experienced and specialized referees in the field of curricula, teaching, psychology and kindergartens, where the agreement was $86 \%$, which indicates that the test is valid for this study.

- Internal honesty: The test was applied to an exploratory sample of (30) male and female students, and the Pearson correlation coefficient was calculated between the items and the total of the test to ensure the validity of the construction, and the following table shows that.

Table 2. Pearson correlation coefficient between the paragraph and the total test score

\begin{tabular}{cccccc}
\hline Variable & Paragraph & $\begin{array}{c}\text { Correlation } \\
\text { coefficient }\end{array}$ & Variable & Paragraph & $\begin{array}{c}\text { Correlation } \\
\text { coefficient }\end{array}$ \\
\hline $\begin{array}{c}\text { Temporal and } \\
\text { spatial concepts } \\
\text { test }\end{array}$ & 1 & $.421^{* *}$ & Temporal and & 11 & $.547^{* *}$ \\
& 2 & $.472^{* *}$ & spatial concepts test & 12 & $.490^{* *}$ \\
& 3 & $.378^{* *}$ & & 13 & $.539^{* *}$ \\
& 4 & $.615^{* *}$ & & 14 & $.534^{* *}$ \\
& 5 & $.316^{* *}$ & & 15 & $.588^{* *}$ \\
6 & $.593^{* *}$ & & 16 & $.586^{* *}$ \\
& 7 & $.615^{* *}$ & 17 & $.573^{* *}$ \\
& 8 & $.259^{* *}$ & & 18 & $.502^{* *}$ \\
9 & $.476^{* *}$ & & 19 & $.571^{* *}$ \\
10 & $.585^{* *}$ & 20 & $.479^{* *}$ \\
\hline
\end{tabular}

It is evident from the previous table that all the paragraphs of the temporal and spatial concepts test are internally consistent because all the paragraphs are statistically significant and thus have construct validity.

\subsection{Stability Test}

The researchers used the repetition method to calculate the stability of the test, after applying the test to a pilot sample of (30), after two weeks, they re-applied the test on the same pilot sample, and the Pearson correlation coefficient was calculated between the two applications and its value was equal to (0.84), which indicates the stability of the concepts test temporal and spatial.

Test time: The time required for the test was determined by recording the time of starting the answer, then determining the time it took the first child to finish the test, determining the time it took for the last child to finish the test, and then calculating the test time with the following equation:

Average Test Time $=$ Fastest Child + Slowest Child

\section{2}

The test time was as follows: $(13+23) / 2=18$

Thus, the time for the test is 18 minutes. 


\subsection{Study Application Procedures}

- The school principal's permission to implement and apply the program and its tools to Kindergarten children, Division (C).

- The experimental section was taught by the teacher, where the two researchers met with her and showed her how to teach the program, applied a classroom session in front of her, discussed it and listened to her opinion, as the program was applied to group $(\mathrm{C})$, which is the experimental group.

The program was implemented over a period of four weeks, at a rate of five lessons per week.

- The following variables were adjusted: The age of children in each of the two groups reached (25) children in each division, where the chronological age of children ranged between (5-6) years. And the level of two groups and the two groups do not overlap, so that students of Division (C) do not feel that they are under experience and Group (A) without experience, to avoid the Hawthorne effect.

A pre-test was applied to both groups to ensure the homogeneity of the two groups at the level

The classroom was prepared for the experimental group in terms of the required paintings and drawings.

- After completing the implementation of the program after four weeks, the post-test was applied to measure the effectiveness of the program in developing some spatial and temporal concepts.

- Test correction by researchers and monitoring of grades.

\section{Results of the Study}

The first hypothesis: There are no statistically significant differences between the mean scores of the experimental group and the control group on the temporal and spatial concepts test illustrated in the pre-application:

To verify the validity of this hypothesis, the researchers calculated the significance of the differences between the mean scores of the children of the experimental group and the control group in the pretest, using the Mann-Whitney test because the sample is small, less than 30. The results are as shown in the following table:

Table 3. The results of the Mann-Whitney test to indicate the differences between the mean of the experimental and control group in the pretest

\begin{tabular}{ccccccccl}
\hline Test & Group & Number & $\begin{array}{c}\text { Average } \\
\text { ranks }\end{array}$ & $\begin{array}{c}\text { Total } \\
\text { ranks }\end{array}$ & $\begin{array}{c}\mathrm{U} \\
\text { value }\end{array}$ & $\begin{array}{c}\mathrm{Z} \\
\text { value }\end{array}$ & Sig & Decision \\
\hline Tribal & Control & 23 & $14 \cdot 78$ & 279 & 132 & 0.365 & 0668 & $\begin{array}{l}\text { There is } \\
\text { no Sig }\end{array}$ \\
& Experimental & 24 & $16 \cdot 23$ & 301 & & & &
\end{tabular}

It is evident from the results in the previous table that there are no statistically significant differences between the experimental group and the control group before applying the program, and this indicates that the two groups are equal before applying the educational program based on pictures and drawings.

The second hypothesis: There are no statistically significant differences between the mean scores of the experimental group and the control group on the test of temporal and spatial concepts based on images in the post application.

To verify the validity of this hypothesis, the researchers calculated the significance of the differences between the mean scores of the children of the experimental group and the control group in the post-test, using the Mann-Whitney test. The results were as shown in the following table:

Table 4. The results of the Mann-Whitney test to indicate the differences between the mean of the experimental and control group in the post test

\begin{tabular}{ccccccccc}
\hline Test & Group & Number & $\begin{array}{c}\text { Average } \\
\text { ranks }\end{array}$ & $\begin{array}{c}\text { Total } \\
\text { ranks }\end{array}$ & $\begin{array}{c}\mathrm{U} \\
\text { value }\end{array}$ & $\begin{array}{c}\mathrm{Z} \\
\text { value }\end{array}$ & Sig & Decision \\
\hline Tribal & Control & 23 & 15 & 281 & 00.0 & 516.5 & 0.00 & $\begin{array}{c}\text { There is } \\
\text { Sig }\end{array}$ \\
\hline
\end{tabular}

It is evident from the results in the previous table that there are statistically significant differences between the experimental group and the control group after implementing the program and in favor of the experimental group, which indicates that children have acquired some spatial and temporal concepts as a result of implementing the program. 
The third hypothesis: There are no statistically significant differences between the mean scores of the experimental group in the temporal and spatial concepts test before and after applying the program.

To verify the validity of this hypothesis, the Wilcoxon test was used to indicate the differences between the averages. The results were as shown in Table 5:

\begin{tabular}{ccccccc}
\hline Test & Number & $\begin{array}{c}\text { Average } \\
\text { ranks }\end{array}$ & $\begin{array}{c}\text { Total } \\
\text { ranks }\end{array}$ & $\begin{array}{c}Z \\
\text { value }\end{array}$ & Sig & Decision \\
\hline Tribal & - & 00 & 00 & -3.06 & 0.031 & $\begin{array}{c}\text { There is } \\
\text { Sig }\end{array}$ \\
& 24 & 4.00 & 216 & & & \\
\hline
\end{tabular}

It is evident from the previous table that there are statistically significant differences between the average of the grading ranks between the pre and post application to test temporal and spatial concepts for the benefit of the post application, and this means that the educational program based on pictures and drawings in developing some spatial and temporal concepts among kindergarten children was effective.

\subsection{Discussing and the Results}

This result, which indicates the existence of statistically significant differences in favor of the experimental group, is attributed to the effectiveness of the applied program, which had a positive effect on the development of some temporal and spatial concepts, by providing an opportunity for children to interact with educational learning situations, and the program has features affecting children such as A program based on pictures and graphics full of colors that attract children, which encouraged children to interact and allowed to better use their abilities, and teaching children in an unconventional way provided a greater atmosphere for participation, interaction and use of senses.

The results of the current study regarding the effectiveness of the training program in developing concepts in general, and specifically the temporal and spatial concepts, are in agreement with the results of the Tarawneh study (2016), the results of the Al-Felfili and Al-Ansi (2015) study, and the results of the Al-Shahwan study (2017).

\section{Recommendations}

In light of the results of the study, researchers recommend the following:

- Including such programs in kindergarten curricula.

- Training kindergarten teachers to use these programs in kindergarten as enrichment programs.

- Interest in using the means that contribute to the development of temporal and spatial concepts.

- Expanding studies related to temporal and spatial concepts among kindergarten children.

\section{References}

Abd Al-Majeed, Abdel Fattah Saber (1978). A study of the growth of perception of the concept of time among children in kindergarten and primary school, an unpublished master's thesis, Faculty of Education, Ain Shams University, Cairo.

Abu Al-Jain, Haifa Yousef. (2012). The effectiveness of a training program to interact with technical drawings (pictures) in developing emotional intelligence in a sample of kindergarten children in Jordan. Unpublished PhD thesis, University of Jordan, Amman, Jordan.

Adas, Abd al-Rahim and Musleh, Adnan Aref (1984). Kindergarten, Amman: Dar Al Fikr for publishing and distribution.

Al-Felfeli, Hana (2009). Developmental Psychology (Childhood and Adolescence), Sana'a University, College of Education: Education Center for Printing, Publishing and Distribution.

Al-Felfeli, Hanaa and Al-Ansi Hammoud (2015). The effectiveness of a games-based educational corner in the development of spatial intelligence among preschool children in Sana'a / Yemen, Journal of Human Sciences, Reality and Hope, First Edition, International Humanities Conference, Israa University, Faculties of Arts and Educational Sciences, Amman: Dar Kunooz Al Marifa for publication and distribution.

Al-Mallah, Tamer (2016). Computers in Early Childhood, Faculty of Education, Alexandria University - Alexandria.

Al-Shahwan, Sahar (2017). The effectiveness of a computerized educational program in developing concepts of health and safety among pre-school children, an unpublished master's thesis, Al-Isra University, Amman - Jordan. 
Bani Khalid, Khaled Ali (2009). Preparing an educational program based on activities related to the axis of time, change and continuity and its impact on the awareness of time among the tenth grade students and their interpretation of historical events in the study of history, unpublished PhD thesis, Yarmouk University - Irbid, Jordan.

Bawazir, Salwa and Qurban, Nadia. (2011). Development of historical and geographical concepts for kindergarten children. Amman: House of the March for Publishing and Distribution.

Boutros, Hafiz Boutros (2008). Development of scientific concepts and skills for pre-school children, 3rd Edition, Amman: Dar Al-Masirah for publishing, distribution and printing.

Eid, Dalal Fathy (2006). Kinetic education in kindergartens, Cairo: Arab Thought House.

El-Sherbiny, Zakaria. (1988). Scientific Concepts for Children, a suggested program for a preschooler, Cairo: The Anglo-Egyptian Library.

Fahmy, Atef (2012). Organizing the child's learning environment, 3rd Edition, Amman: Dar Al-Masirah.

Godwin, W., \& Klausmeier, H. (1995) Facilitating student learning: An introduction To Education Psychology. New York: HarPer and Publishers.

Hammam, Fatima (2018). The effectiveness of an informative program in developing the concepts of health awareness among kindergarten children. Unpublished MA Thesis, College of Educational Sciences, Najran University Kingdom of Saudi Arabia.

Hariri, Rafideh (2003). The emergence of kindergarten, Amman: Sikan Library.

Hwrgesheimer J. (2000). Cutting the Essence: Concepts in Social Studies. Review 10-13.

Ibrahim, Violet and Boutros, Boutros Hafez (1997). Scientific and Environmental Concepts, Cairo: The AngloEgyptian Library. Retrieved from www.aspdkw.com on 10/30/2018, 12:30 pm.

Isa, Hana Abdel Aziz (1997). The effectiveness of the proposed program in training students, science and basic education teachers, on strategies for developing creative thinking among their pupils. Unpublished MA Thesis, Faculty of Education, Alexandria University, Alexandria, Egypt.

Karamuddin, Leila (2001). Mental and linguistic development for pre-school children, Khotwa Magazine, p.14.

Lomras, T. (1985). The meaning of time related concepts across the lifespan. International Journal of Aging and Human Development, 2l( 2), 87-107. https://doi.org/10.2190/UXPR-3394-KY51-UQTL

Mahadin, Hussein Taha (2003). Investing time among Jordanian youth, Ministry of Culture: Jordan.

Massy, D. (1995). A study of children's spatial and temporal concepts. Dissertation Abstracts international, Dec.Vol32.

Saadeh, Jawdat and Youssef, Jamal (1988). Teaching the concepts of Arabic language, mathematics, science and social education, Beirut: Dar Al-Jeel.

Scott, C, (1997). The acquisition of some conversational time by preschool, paper presented at the annual meeting of American education research association (Chicago), 24-28.

Sharif, Mr. Abdul Qadir. (2014). The entrance to the kindergarten. Cairo: Dar Al-Jawhara for Publishing and Distribution.

Tarwana, Ahmed Abdullah. (2016). The effectiveness of a training program based on analog thinking in developing concepts (spatial, temporal, scientific, and social) among kindergarten students in Karak governorate. Mu'ta Research and Studies Series, Social Sciences and Humanities Series, 28 (3), 163-188.

\section{Copyrights}

Copyright for this article is retained by the author(s), with first publication rights granted to the journal.

This is an open-access article distributed under the terms and conditions of the Creative Commons Attribution license (http://creativecommons.org/licenses/by/4.0/). 